Article

\title{
Rapid Synthesis of Carbon Dots by Hydrothermal Treatment of Lignin
}

\author{
Wenxin Chen ${ }^{1}$, Chaofan $\mathrm{Hu}^{2}$, Yunhua Yang ${ }^{3}$, Jianghu Cui ${ }^{4}$ and Yingliang Liu ${ }^{4, *}$ \\ 1 Department of Chemistry, Jinan University, Guangzhou 510632, China; tchenwenxin@jnu.edu.cn \\ 2 College of Mechanics, Taiyuan University of Technology, Taiyuan 030024, China; huchaofan@tyut.edu.cn \\ 3 Guangdong Institute of Microbiology, State Key Laboratory of Applied Microbiology Southern China, \\ Guangdong Provincial Key Laboratory of Microbial Culture Collection and Application, \\ Guangzhou 510070, China; yangyh@gdim.cn \\ 4 Department of Applied Chemistry, College of Science, South China Agricultural University, \\ Guangzhou 510642, China; jianghucui@soil.gd.cn \\ * Correspondence: tliuyl@scau.edu.cn; Tel.: +86-20-3733-8319
}

Academic Editor: Lioz Etgar

Received: 24 November 2015; Accepted: 23 February 2016; Published: 9 March 2016

\begin{abstract}
A rapid approach has been developed for the fluorescent carbon dots (CDs) by the hydrothermal treatment of lignin in the presence of $\mathrm{H}_{2} \mathrm{O}_{2}$. The as-synthesized CDs were found to emit blue photoluminescence with excellent photostability. Moreover, the CDs displayed biocompatibility, low cytotoxicity, and high water solubility properties. Finally, the as-resulted CDs were demonstrated to be excellent probes for bioimaging and biosensing applications.
\end{abstract}

Keywords: carbon dots; lignin; $\mathrm{H}_{2} \mathrm{O}_{2}$; hydrothermal synthesis; bioimaging

\section{Introduction}

Carbon dots (CDs) are an interesting class of carbon nanoparticles, which are being investigated for various applications due to their favorable optical stability, low toxicity, biocompatibility, and ease of functionalization [1-3]. Many researchers have studied the synthesis methods and photoluminescence properties of CDs. A variety of synthesis approaches such as laser ablation, electrochemical exfoliation, pyrolysis, incomplete combustion oxidation, acidic oxidation, hydrothermal treatments and microwave synthesis have been developed to prepare CDs [4-11]. Various raw material including graphite oxide, citric acid, glycerol, coffee grounds, soy milk, grass and egg have been used in the synthesis of CDs [12-16]. However, it is still desirable to rapidly synthesize high-quality CDs by an easy and environmentally benign method with low-cost and readily available starting materials. One such suitable raw material is lignin, which is an abundant natural organic polymer, and an excellent source of carbon. There is an increasing interest in using lignin to prepare new carbon-based materials [17-19]. However, it is quite difficult to degrade lignin and its derivatives due to strong carbon to carbon linkages in their molecular structure. Amongst various techniques, the hydrothermal carbonization process is a promising approach for the synthesis of novel carbon-based materials, especially CDs [20].

Herein, we report a rapid route to synthesize highly luminescent CDs by the hydrothermal treatment of lignin with the assistance of $\mathrm{H}_{2} \mathrm{O}_{2}$. It is well-known that $\mathrm{H}_{2} \mathrm{O}_{2}$ can be dissociated into hydroxyl radicals $(\cdot \mathrm{OH})$ under the photoassisted catalysis $\mathrm{Fe}^{3+} / \mathrm{Fe}^{2+}$ in water, and the resulting $\mathrm{OH}$ radical is an extremely powerful oxidizing species [21]. The synthesis approach was simple and environmentally friendly. It was demonstrated that the as-prepared CDs exhibit good luminescence property, good water solubility, narrow particle size distribution and low cytotoxicity. The CDs also showed excellent bioimaging capabilities in Hela cells. This work provides a new approach for the preparation of CDs from natural materials, and also demonstrates the potential of CDs in bio-imaging applications. 


\section{Results and Discussion}

Figure 1a indicates the pyrolysis products of lignin at 10, 20, 30, 40, 50 and 60 min, respectively. It could be seen that the color of the initial product solution became pale as the time increased. The residual lignin was retained on the filter paper (Figure 1b). The synthesis yields of the CDs were $12.06 \%, 10.2 \%, 6.67 \%, 2.3 \%, 1.05 \%, 0.8 \%$ corresponding to $10,20,30,40,50$ and 60 min, respectively. The optical images of the CDs solution exhibited blue luminescence under UV light excitation (Figure 1c) and the pyrolysis time of 40 min exhibited the maximum brightness. The CDs solution remains transparent for half a year without precipitation.

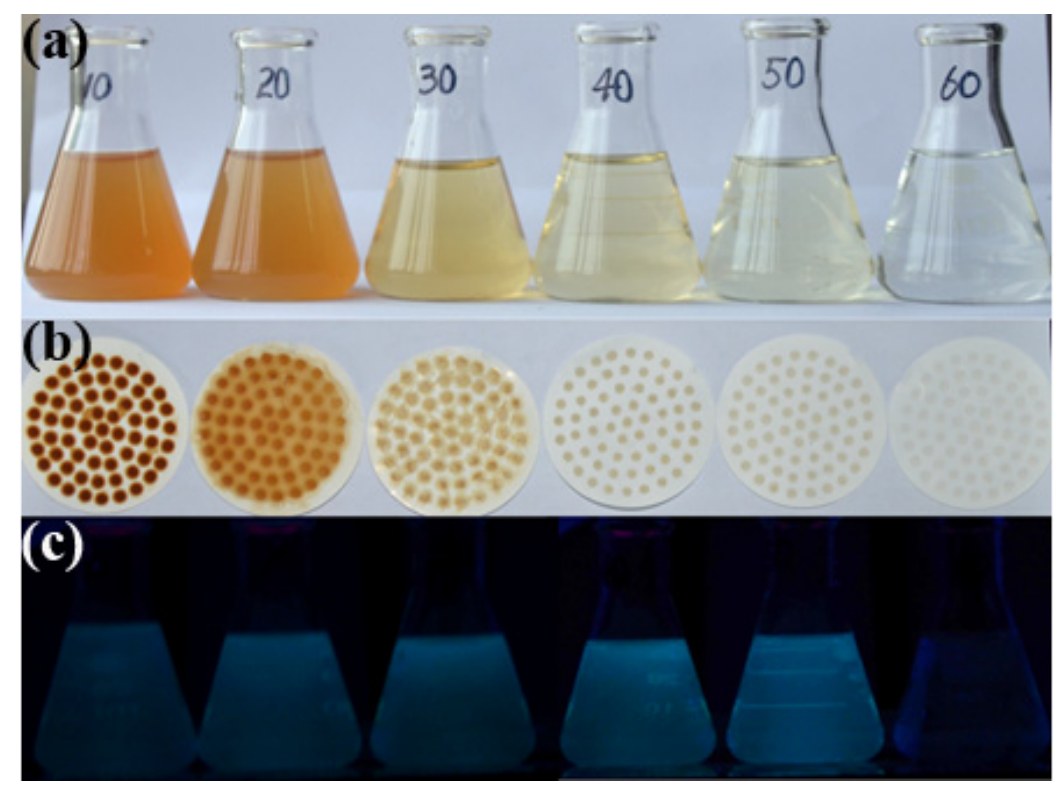

Figure 1. Pyrolysis results for (a) the initial product solution; and (b) the residual lignin after 10, 20, 30, 40, 50 and 60 min hydrothermal reaction; and (c) the corresponding filtrate image under $365 \mathrm{~nm}$ UV lamp irradiation.

Transmission electron microscopy (TEM) and high-resolution TEM (HRTEM) performed on the CDs, and the results are shown in Figure 2. The size of the CDs ranged from 2 to $10 \mathrm{~nm}$. The HRTEM images indicated that the carbon dots have crystalline structure and the lattice spacing distance was about $0.21 \mathrm{~nm}$, close to that of the graphite (100) plane [22].
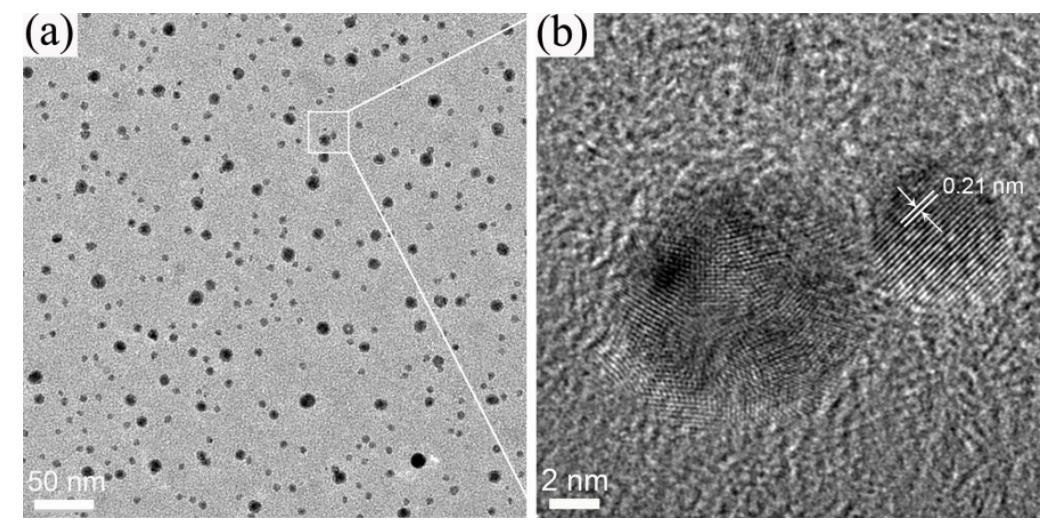

Figure 2. (a) Transmission electron microscopy (TEM); and (b) high-resolution TEM (HRTEM) images of the carbon dots (CDs) prepared by hydrothermal treatment of lignin. 
From the wide-scan X-ray photo-electron spectroscopy (XPS) spectrum depicted in Figure 3, two strong peaks at 285.5 and $532.0 \mathrm{eV}$ were attributed to oxygen and carbon, respectively. The elemental components of the as-prepared CDs were $\mathrm{C}(82.58 \%)$ and $\mathrm{O}(17.42 \%)$. The deconvoluted $\mathrm{C}_{1 \mathrm{~s}}$ spectrum (Figure $3 \mathrm{~b}$ ) showed three components, which could be assigned as graphite $\left(\mathrm{sp}^{2}\right)$ carbon at $\sim 283.2 \mathrm{eV}, \mathrm{sp}^{3}$ carbon at $\sim 286.1 \mathrm{eV}$, and carboxyl carbon at $288.6 \mathrm{eV}$. The $\mathrm{O}_{1 \mathrm{~s}}$ spectrum (Figure 3c) exhibited three peaks at 530.6, 532.1 and $533.2 \mathrm{eV}$, which were attributed to the $\mathrm{C}=\mathrm{O}, \mathrm{C}-\mathrm{OH}$ and $\mathrm{C}-\mathrm{O}-\mathrm{C}$ groups, respectively $[23,24]$.
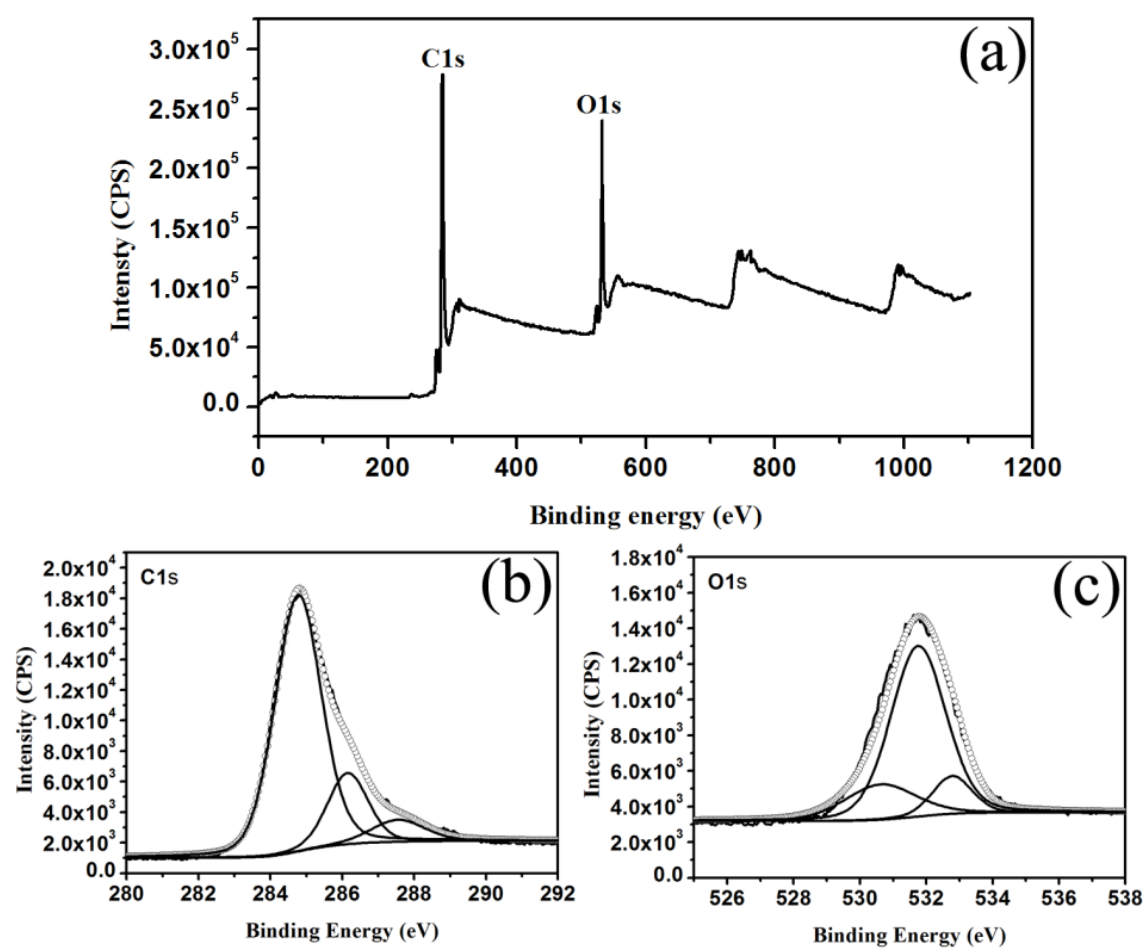

Figure 3. (a) X-ray photo-electron spectroscopy (XPS); (b) $\mathrm{C}_{1 \mathrm{~s}}$; and (c) $\mathrm{O}_{1 \mathrm{~s}}$ spectra of the as-prepared CDs.

The CDs obtained after 40 min pyrolysis were characterized by Raman spectroscopy, as shown in Figure 4a. Their Raman spectrum showed a strong D band at $1382 \mathrm{~cm}^{-1}$, which corresponds to the $\mathrm{sp}^{3}$ defects in CDs. Also, a G band was observed at $1578 \mathrm{~cm}^{-1}$, which matched well with the disordered carbon and the $\mathrm{sp}^{2}$ clusters, indicating that there were aromatic groups inside CDs. It was observed that the CDs have an $I_{D} / I_{G}$ ration of 0.91 , which might be due to oxygen-rich edges of the CDs. The UV-Vis spectra of aqueous solution of CDs showed two peaks at 282 and $348 \mathrm{~nm}$, indicating that there were different surface states present in the CDs solution. The fluorescence spectra of the $\mathrm{CDs}_{40 \mathrm{~min}}$ were measured with an F-4500 fluorescence spectrometer (HITACHI, Tokyo, Japan), with a slit width of $10 \mathrm{~nm}$ for both excitation and emission beams. The excitation wavelength was varied from 280 to $500 \mathrm{~nm}$, in $20 \mathrm{~nm}$ increments. The corresponding spectra are given in Figure $4 \mathrm{~b}$. Bright and colorful photoluminescence (PL) emissions were observed from the CDs. The emission maxima shifted as the excitation wavelength increased and exhibited a maximum PL intensity at an excitation wavelength of $320 \mathrm{~nm}$ and emission wavelength of $430 \mathrm{~nm}$. The CDs showed excellent photostability as the fluorescence intensity did not change, even after continuous excitation under a $150 \mathrm{~W}$ Xenon lamp. As shown in Figure 5, the fluorescence of the fluorescein isothiocyanate (FITC) was quickly quenched within several minutes excitation and the CdTe quantum dots (QDs) were preserving 25\% of the original PL intensity after 20 min excitation. The PL intensity of the CDs that we synthesized retaining $95 \%$ of the initial intensity under $c a .100$ min excitation. The result indicated that the PL of the CDs was much more stable than of the fluorescent FITC and the CdTe QDs. We considered that the formation of CDs and their surface functionalization take place simultaneously during the 
hydrothermal carbonization process. The presence of large number of carboxylic acids introduces several different surface defects. These defects behave as excitation energy traps, and are responsible for the different photoluminescence behaviors. In fact, several mechanisms have been proposed to explain these unique PL properties, such as the size distribution of the CDs, a distribution of different emissive trap sites and the formation of several different polyaromatic fluorophores within the carbogenic core. However, the exact mechanism of the CDs' PL behavior is still unclear and further studies are required to understand this property in depth.
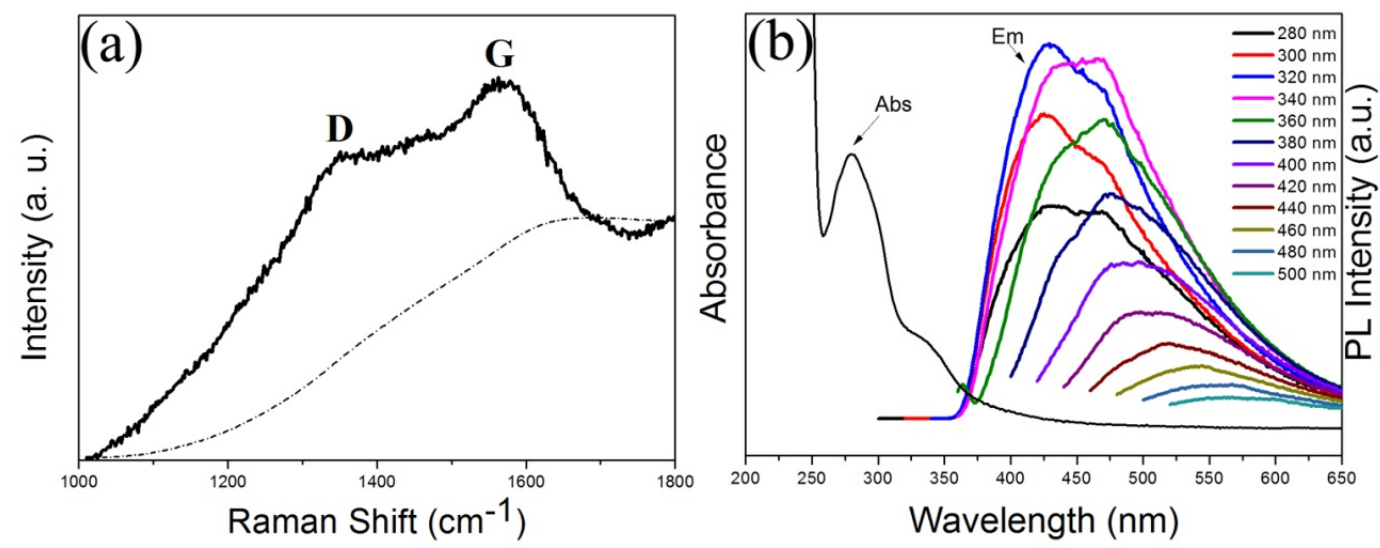

Figure 4. (a) Raman absorbance and the background is given by the dashed line; (b) photoluminescence (PL) spectra of the CDs at different excitation wavelengths.

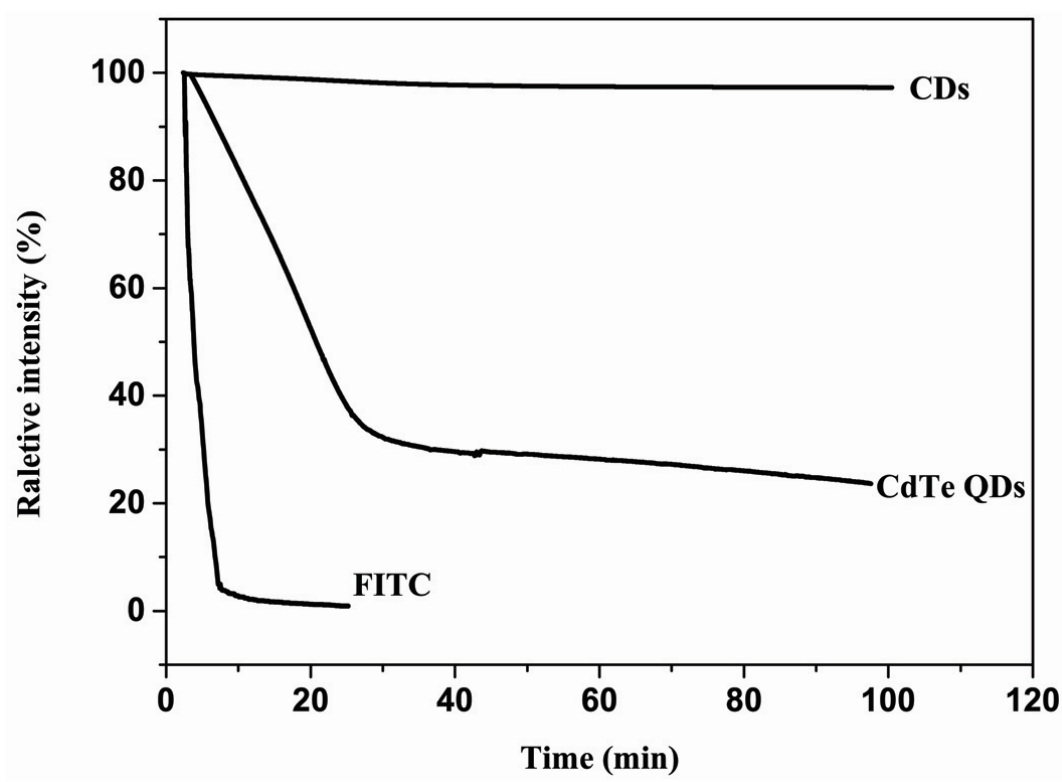

Figure 5. Photostability comparison of the fluorescent CDs, CdTe QDs and fluorescein isothiocyanate (FITC) in a fluorescence spectrophotometer with a $150 \mathrm{~W}$ Xe lamp under $360 \mathrm{~nm}$ excitation.

To investigate the feasibility of using CDs for bio-imaging, A549 human lung adenocarcinoma cells were used to evaluate the cytocompatibility of the CDs. The cell viability of the CDs was determined by a methylthiazoleterazolium (MTT) assay. As can be seen in Figure 6, the MTT assays of cell viability reports indicate that the CDs have very low cytotoxicity. This result confirms that CDs can be used for imaging or other biomedical applications. 


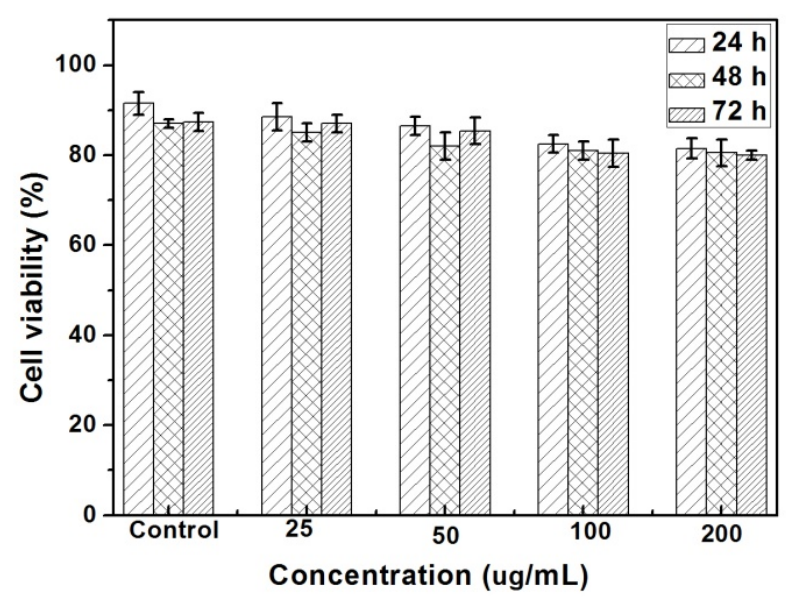

Figure 6. Cytotoxicity evaluations test of A549 cells with different concentrations of CDs40min after 24, 48 and $72 \mathrm{~h}$ incubation.

The obtained CDs from 40 min hydrothermal carbonization were introduced into the Hela cells, and their bio-imaging capabilities were evaluated using in vitro confocal microscopy test. The results showed that the photoluminescent spots were observed only in the cell membrane and cytoplasmic area of the cell, indicating that the CDs were able to easily penetrate into the cell (Figure 7). This observation was is in agreement with previous studies on the interaction of living cells with nanomaterials [25]. The results illustrate that $\mathrm{CDs}$ can be used as fluorescence probe for bio-imaging applications.
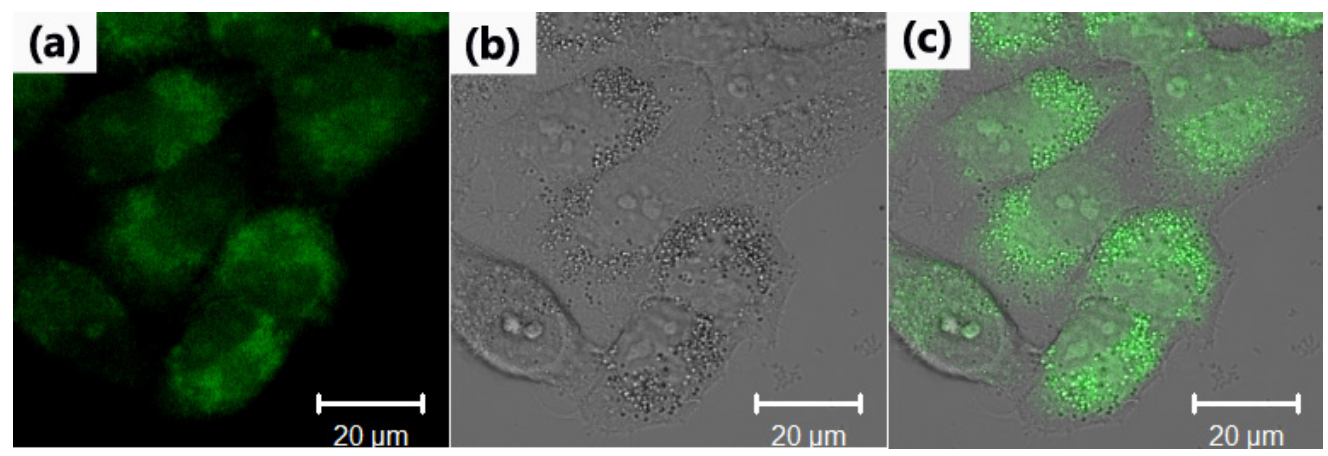

Figure 7. (a) A confocal fluorescence microphotograph of Hela cells labeled with the CDs ( $\lambda$ ex: $405 \mathrm{~nm}$ ); (b) A bright field microphotograph of the cells; (c) An overlay image of (a) and (b).

\section{Materials and Methods}

\subsection{Preparation of the Fluorescent CDs}

In a typical procedure, fluorescent CDs were synthesized as follows: $100 \mathrm{mg}$ lignin was dispersed in $30 \mathrm{~mL}$ purified water and ultrasonicated for $10 \mathrm{~min}$, then $2 \mathrm{~mL} \mathrm{H}_{2} \mathrm{O}_{2}$ was added, and the mixture was sealed into a $50 \mathrm{~mL}$ Teflon lined stainless steel autoclave, which was then placed in a muffle furnace followed by hydrothermal treatment at $180{ }^{\circ} \mathrm{C}$ for 10, 20, 30, 40, 50 and $60 \mathrm{~min}$. After the reaction, the autoclave was cooled down naturally, and the obtained yellow solution was filtered with a $0.22 \mu \mathrm{m}$ membrane filter (Millipore, Boston, MA, USA) to remove the unreacted lignin. The filtrate was subjected to dialysis for 2 days using a 3500 Da dialysis membrane (Spectrumlabs, Rancho Dominguez, CA, USA) to remove the excess $\mathrm{H}_{2} \mathrm{O}_{2}$. The resulting yellow solution was freeze-dried to obtain the final CDs. 


\subsection{Characterization Methods}

Morphological features of the CDs were using a transmission electron microscopy (TEM, Philips TECNAI 10, Amsterdam, Holland) and field emission electron microscope (JEOL JEM-2100F, JEOL, Tokyo, Japan). X-ray photo-electron spectroscopy (XPS, AXIS ULTRA DLD, Kratos, Manchester, British) was used to investigate the functional groups present on the surface of the CDs. The fluorescence spectra of the CDs were measured with a fluorescence spectrometer (F-4500, HITACHI, Tokyo, Japan), with a slit width of $10 \mathrm{~nm}$ and $10 \mathrm{~nm}$ for excitation and emission, respectively. The excitation wavelength increased by a $20 \mathrm{~nm}$ increment starting from 280 to $500 \mathrm{~nm}$.

\subsection{Fluorescence Imaging Experiments}

Hela cells were seeded in each well of a confocal dish (a coverglass-bottom dish) and cultured at $37^{\circ} \mathrm{C}$ for $24 \mathrm{~h}$. An aqueous solution of the CDs $(0.1 \mathrm{mg} / \mathrm{mL})$ was passed through a $0.2 \mu \mathrm{m}$ sterile membrane filter. The filtered fluorescent suspension $(40,50$, and $60 \mu \mathrm{L})$ was mixed with the culture medium $(200 \mu \mathrm{L})$ and then added to three wells of the confocal dish (the fourth used as a control) in which the Hela cells were grown. After an incubation period of $2 \mathrm{~h}$, the medium was removed and the cells were washed thoroughly three times with phosphate buffered saline (PBS) and kept in PBS for the optical imaging. Cellular uptake of CDs by Hela cells was monitored by confocal microscopy under the excitation wavelength of $405 \mathrm{~nm}$.

\section{Conclusions}

In conclusion, we have demonstrated that a fast, efficient and green method to synthesize fluorescent carbon dots by the hydrothermal treatment of lignin under the action of $\mathrm{H}_{2} \mathrm{O}_{2}$. The resulting CDs were thoroughly characterized and showed excellent potential for applications in biological labeling and biosensors fields.

Acknowledgments: This work was financially supported by the National Science Foundation of China (21401028, 21031001, 21571067 and 51372091), the higher school science and technology innovation project of Guangdong Province (cxzd1014), the youth fund of Guangdong Provincial Academy of Sciences (qnjj201406), and the Microbial Talents Cultivation Fund of Guangdong Institute of Microbiology.

Author Contributions: Chen Wenxin contributed to the concept, supervised the entire research work and wrote the manuscript. Hu Chaofan and Yang Yunhua performed the core experimental works. Cui Jianghu measured the cell imaging experiment. Liu Yingliang contributed to the discussion of the results and conclusions and revised the paper.

Conflicts of Interest: The authors declare no conflict of interest.

\section{Abbreviations}

The following abbreviations are used in this manuscript:

CDs carbon dots

PL photoluminescence

TEM transmission electron microscopy

XPS X-ray photo-electron spectroscopy

PBS phosphate buffered saline

\section{References}

1. Cao, L.; Wang, X.; Meziani, M.J.; Lu, F.S.; Wang, H.F.; Luo, P.G.J.; Lin, Y.; Harruff, B.A.; Veca, L.M.; Murray, D.; et al. Carbon dots for multiphoton bioimaging. J. Am. Chem. Soc. 2007, 129, 11318-11319. [CrossRef] [PubMed]

2. Sun, Y.P.; Wang, X.; Lu, F.S.; Cao, L.; Meziani, M.J.; Luo, P.G.J.; Gu, L.R.; Veca, M. Doped carbon nanoparticles as a new platform for highly photoluminescent dots. J. Phys. Chem. C 2008, 112, 18295-18298. [CrossRef] [PubMed] 
3. Sun, Y.P.; Zhou, B.; Lin, Y.; Wang, W.; Fernando, K.A.S.; Pathak, P.; Meziani, M.J.; Harruff, B.A.; Wang, X.; Wang, H.F.; et al. Quantum-sized carbon dots for bright and colorful photoluminescence. J. Am. Chem. Soc. 2006, 128, 7756-7757. [CrossRef] [PubMed]

4. Cai, X.; Tan, S.Z.; Lin, M.S.; Xie, A.G.; Mai, W.J.; Zhang, X.J.; Lin, Z.D.; Wu, T.; Liu, Y.L. Synergistic antibacterial brilliant blue/reduced graphene oxide/quaternary phosphonium salt composite with excellent water solubility and specific targeting capability. Langmuir 2011, 27, 7828-7835. [CrossRef] [PubMed]

5. Jia, X.F.; Li, J.; Wang, E.K. One-pot green synthesis of optically pH-sensitive carbon dots with upconversion luminescence. Nanoscale 2012, 4, 5572-5575. [CrossRef] [PubMed]

6. Rahim, R.A.; Kurahashi, H.; Uesugi, K.; Fukuda, H. Carbon nano dots scale by focused ion beam system for MIS diode nano devices. Surf. Sci. 2007, 601, 5112-5115. [CrossRef]

7. Wang, F.; Pang, S.P.; Wang, L.; Li, Q.; Kreiter, M.; Liu, C.Y. One-step synthesis of highly luminescent carbon dots in noncoordinating solvents. Chem. Mater. 2010, 22, 4528-4530. [CrossRef]

8. Yang, S.T.; Cao, L.; Luo, P.G.J.; Lu, F.S.; Wang, X.; Wang, H.F.; Meziani, M.; Liu, Y.F.; Qi, G.; Sun, Y.P. Carbon dots for optical imaging in vivo. J. Am. Chem. Soc. 2009, 131, 11308-11309. [CrossRef] [PubMed]

9. Zhang, P.; Li, W.C.; Zhai, X.Y.; Liu, C.J.; Dai, L.M.; Liu, W.G. A facile and versatile approach to biocompatible "fluorescent polymers" from polymerizable carbon nanodots. Chem. Commun. 2012, 48, 10431-10433. [CrossRef] [PubMed]

10. Zhang, X.Y.; Wang, S.Q.; Zhu, C.Y.; Liu, M.Y.; Ji, Y.; Feng, L.; Tao, L.; Wei, Y.J. Carbon-dots derived from nanodiamond: Photoluminescence tunable nanoparticles for cell imaging. J. Colloid Interface Sci. 2013, 397, 39-44. [CrossRef] [PubMed]

11. Zhao, A.D.; Zhao, C.Q.; Li, M.; Ren, J.S.; Qu, X.G. Ionic liquids as precursors for highly luminescent, surface-different nitrogen-doped carbon dots used for label-free detection of $\mathrm{Cu}^{2+} / \mathrm{Fe}^{3+}$ and cell imaging. Anal. Chim. Acta 2014, 809, 128-133. [CrossRef] [PubMed]

12. De, B.; Karak, N. A green and facile approach for the synthesis of water soluble fluorescent carbon dots from banana juice. Rsc. Adv. 2013, 3, 8286-8290. [CrossRef]

13. Prasannan, A.; Imae, T. One-pot synthesis of fluorescent carbon dots from orange waste peels. Ind. Eng. Chem. Res. 2013, 52, 15673-15678. [CrossRef]

14. Yan, X.L.; Li, X.J.; Yan, Z.F.; Komarneni, S. Porous carbons prepared by direct carbonization of MOFs for supercapacitors. Appl. Surf. Sci. 2014, 308, 306-310. [CrossRef]

15. Zhang, Z.; Hao, J.H.; Zhang, J.; Zhang, B.L.; Tang, J.L. Protein as the source for synthesizing fluorescent carbon dots by a one-pot hydrothermal route. Rsc. Adv. 2012, 2, 8599-8601. [CrossRef]

16. Zhou, J.J.; Sheng, Z.H.; Han, H.Y.; Zou, M.Q.; Li, C.X. Facile synthesis of fluorescent carbon dots using watermelon peel as a carbon source. Mater. Lett. 2012, 66, 222-224. [CrossRef]

17. Fu, K.F.; Yue, Q.Y.; Gao, B.Y.; Sun, Y.Y.; Zhu, L.J. Preparation, characterization and application of lignin-based activated carbon from black liquor lignin by steam activation. Chem. Eng. J. 2013, 228, 1074-1082. [CrossRef]

18. Ragan, S.; Megonnell, N. Activated carbon from renewable resources-Lignin. Cellul. Chem. Technol. 2011, 45, 527-531.

19. Ruiz-Rosas, R.; Bedia, J.; Lallave, M.; Loscertales, I.G.; Barrero, A.; Rodríguez-Mirasol, J.; Cordero, T. The production of submicron diameter carbon fibers by the electrospinning of lignin. Carbon 2010, 48, 696-705. [CrossRef]

20. Titirici, M.-M.; Antonietti, M.; Baccile, N. Hydrothermal carbon from biomass: A comparison of the local structure from poly-to monosaccharides and pentoses/hexoses. Green Chem. 2008, 10, 1204-1212. [CrossRef]

21. Zhou, X.; Zhang, Y.; Wang, C.; Wu, X.; Yang, Y.; Zheng, B.; Wu, H.; Guo, S.; Zhang, J. Photo-Fenton reaction of graphene oxide: A new strategy to prepare graphene quantum dots for DNA cleavage. ACS Nano 2012, 6, 6592-6599. [CrossRef] [PubMed]

22. Pan, D.Y.; Guo, L.; Zhang, J.C.; Xi, C.; Xue, Q.; Huang, H.; Li, J.H.; Zhang, Z.W.; Yu, W.J.; Chen, Z.W.; et al. Cutting $\mathrm{sp}(2)$ clusters in graphene sheets into colloidal graphene quantum dots with strong green fluorescence. J. Mater. Chem. 2012, 22, 3314-3318. [CrossRef]

23. Bhunia, S.K.; Saha, A.; Maity, A.R.; Ray, S.C.; Jana, N.R. Carbon nanoparticle-based fluorescent bioimaging probes. Sci. Rep. 2013, 3. [CrossRef] [PubMed] 
24. Yuan, M.; Zhong, R.B.; Gao, H.Y.; Li, W.R.; Yun, X.L.; Liu, J.R.; Zhao, X.M.; Zhao, G.F.; Zhang, F. One-step, green, and economic synthesis of water-soluble photoluminescent carbon dots by hydrothermal treatment of wheat straw, and their bio-applications in labeling, imaging, and sensing. Appl. Surf. Sci. 2015, 355, 1136-1144. [CrossRef]

25. Yang, Y.H.; Cui, J.H.; Zheng, M.T.; Hu, C.F.; Tan, S.Z.; Xiao, Y.; Yang, Q.; Liu, Y.L. One-step synthesis of amino-functionalized fluorescent carbon nanoparticles by hydrothermal carbonization of chitosan. Chem. Commun. 2012, 48, 380-382. [CrossRef] [PubMed]

(C) 2016 by the authors; licensee MDPI, Basel, Switzerland. This article is an open access article distributed under the terms and conditions of the Creative Commons by Attribution (CC-BY) license (http://creativecommons.org/licenses/by/4.0/). 